\title{
Foley kateterin standart perkütan endoskopik gastrostomi yerine kullanımı; tek merkez deneyimi
}

\section{Use of Foley catheter instead of standard percutaneous gastrostomy: A single-center study}

\section{(D) Mehmet BAYRAM ${ }^{1}$, (D) Kader IRAK ${ }^{1}$, (D) Özgür YILDIRIM ${ }^{2}$, (D Hüseyin ALKIM ${ }^{3}$}

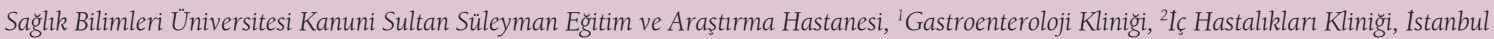
Sağlı Bilimleri Üniversitesi Şisli Hamidiye Etfal Eğitim ve Araştırma Hastanesi, ${ }^{3}$ Gastroenteroloji Kliniği, Istanbul

\begin{abstract}
Giriş ve Amaç: Perkütan endoskopik gastrostomi uygulaması uzun yıllardır enteral nutrisyon için kullanılan bir yöntemdir. Perkütan endoskopik gastrostomi kateteri kendiliğinden çıktığı veya hasta tarafından çıkarıldığı durumlarda aynı yol üzerinden uygulanan Foley kateter ile de enteral nutrisyonun devamı sağlanabilmektedir. Biz de perkütan endoskopik gastrostomi kateteri yerine Foley kateter kullanımını retrospektif olarak değerlendirmeyi hedefledik. Gereç ve Yöntem: 2016-2019 yılları arası Istanbul Kanuni Sultan Süleyman Eğitim ve Araştırma Hastanesi Gastroenteroloji endoskopi ünitesinde perkütan endoskopik gastrostomi kateteri takılmış ve sonrasında perkütan endoskopik gastrostomi kateteri istenmeden çıktığında Foley kateter takılan hastalar gelişen komplikasyonlar ve Foley kateterin kullanım süresi açısından retrospektif olarak değerlendirildi. Bulgular: Çalışmaya verilerine ulaşılabilen 17 hasta dahil edildi. 8 hastada Foley kateterde tıkanma, balonun sönmesi, migrasyona bağlı ileus ve ülser kanaması komplikasyonlar gelişti. Komplikasyon gelişmeyen 9/17 hasta grubunda Foley kateter ile takip süresi medyan 6 hafta (1-74 hafta) olarak saptandı. Sonuç: Perkütan endoskopik gastrostomi kateteri yerine Foley kateter kullanımı özellikle yaşam beklentisi çok kısa, endoskopik iṣlem riski yüksek olan hastalarda uygulanabilecek daha az invaziv, pratik ve ekonomik bir yöntemdir. Ancak hastalar komplikasyonlar açısından yakından takip edilmelidir.
\end{abstract}

Anahtar kelimeler: Foley kateter, perkütan gastrostomi
Background and Aims: Percutaneous enteral gastrostomy has long been the preferred method for providing enteral nutrition. In cases where the percutaneous enteral gastrostomy catheter is removed spontaneously or by the patient, continuity of enteral nutrition can be maintained via the same route using a Foley catheter. We aimed to retrospectively evaluate patient outcomes following the use of a Foley catheter instead of a percutaneous enteral gastrostomy catheter. Material and Methods: Patients who underwent percutaneous enteral gastrostomy catheter insertion at the gastroenterology endoscopy unit of Istanbul Kanuni Sultan Suleyman Training and Research Hospital between 2016 and 2019, and patients who had a Foley catheter inserted after the percutaneous enteral gastrostomy catheter was inadvertently removed were included in this study. Patients were retrospectively evaluated for the complications and duration of the use of the Foley catheter. Results: A total of 17 patients, whose data could be retrieved, were included in the study. In eight patients, complications including occlusion of Foley catheter, deflation of catheter balloon, ileus due to migration, and ulcer bleeding were reported. In patients without complications (9/17) the median follow up period with a Foley catheter was 6 weeks (range 1-74 weeks). Conclusion: Use of a Foley instead of percutaneous enteral gastrostomy catheter is a less invasive, practical, and economical method, especially for patients with low life expectancy and high endoscopic procedure risks. However, patients should be followed up closely for complications.

Keywords: Foley catheter, percutaneous gastrostomy

nutrisyonun devam ettirildiği hastalarımızı retrospektif olarak değerlendirdik.

\section{GEREÇ ve YÖNTEM}

2016-2019 yılları arası Istanbul Kanuni Sultan Süleyman Eğitim ve Araştırma Hastanesi gastroenteroloji endoskopi ünitesinde PEG takılmıs ve sonrasında PEG kateteri kendiliğinden çıkan veya hasta tarafından çıkarılan, endoskopiyi kolay tolere edemeyecek durumda olan ve beklenen yaşam süresinin kısa olması nedeniyle Foley kateter takılarak enteral nütrisyonun devam ettirildiği hastalar retrospektif olarak değerlendirildi.

Hastalara acil servis, endoskopi ünitesi, yoğun bakım ünitesi veya palyatif bakım ünitesinde yatak başında Foley kateter 

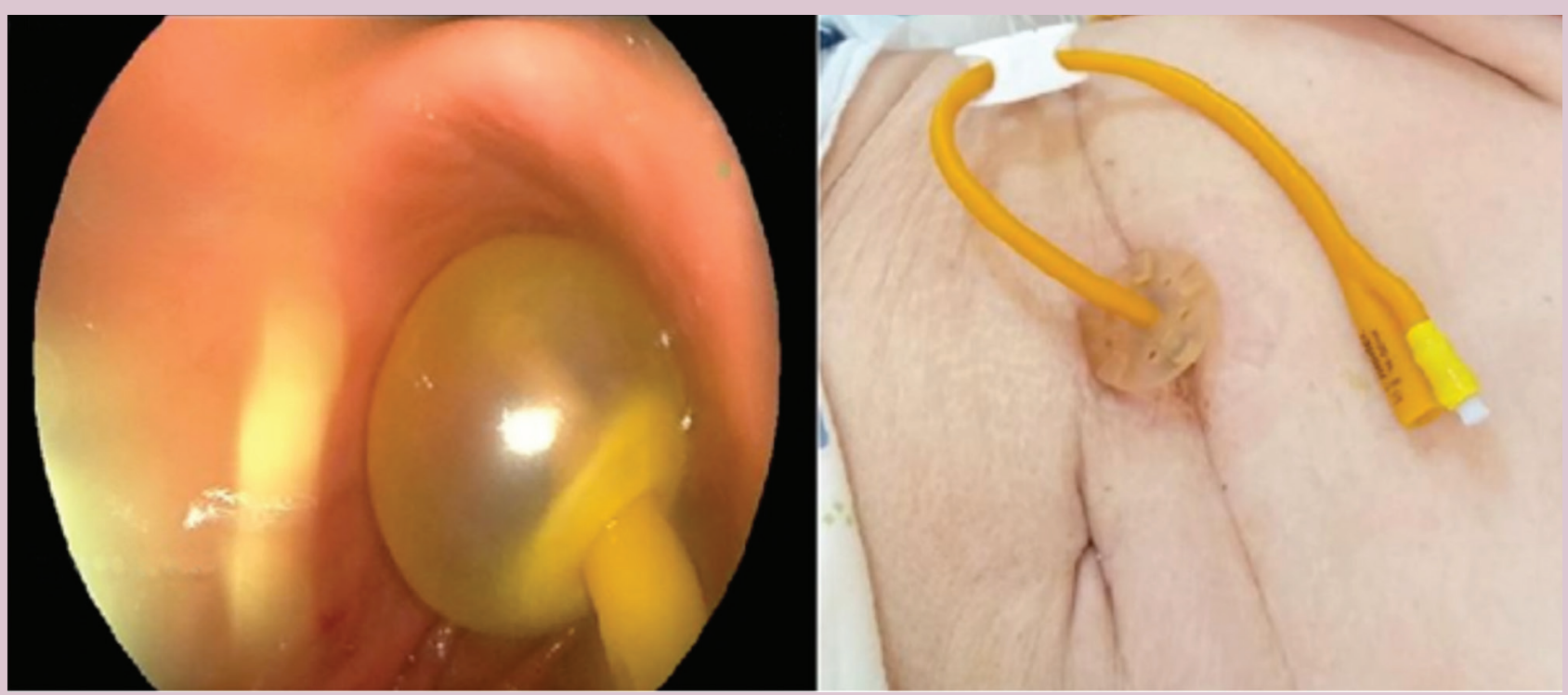

Resim 1. Foley kateter uygulaması.

uygulaması yapıldı. 20 French balonlu Foley kateter üzerine önce cilt sabitleyicisi ve klemp takıldı ve bu kateter çıkmış olan PEG kateterin yolu üzerinde yerleştirildi. Foley kateterin balonu 15-20 ml su ile şişirildi (Resim 1). Cilt sabitleyicisi cilde yakın olacak şekilde sabitlendi ve kateter üzeri kapatıldı. Hastalara işlem için premedikasyon uygulanmadı.

Çalışma için Istanbul Kanuni Sultan Süleyman Eğitim ve Araştırma Hastanesi Etik kurulundan onay alındı (KAEK/ 2018.7.10).

\section{BULGULAR}

Çalışmaya verilerine ulaşılabilen 9'u kadın 17 hasta dahil edildi. Hastaların yaş ortalaması 78 idi. Hastaların demografik verileri ve PEG takılma endikasyonları Tablo l'de gösterilmiştir. Hastaların \%47'sinde (8/17) Foley kateter takılmasına bağlı komplikasyon gelişti. Komplikasyonlar aşağıda sıralanmaktadir.

Kateter kenarından sızma: Bir (\%6) hastada Foley kateter kenarından sızıntı oldu. Bunun üzerine bir boy büyük Foley kateter ile değiştirildi. Sızıntının yine devam etmesi nedeniyle Foley kateter çekildi. Oluşmuş olan fistülden sızıntı devam etti. Terminal dönem akciğer kanseri olan hastada parenteral nutrisyona geçildi. Ancak hasta kısa süre içerisinde exitus oldu.

Kateter balon sönmesi: Üç (\%18) hastada Foley kateter takıldıktan sonra kısa süre içinde (1-9 gün) balonun sönmesine bağlı yerinden çıktı. Bu hastalara yeni standart PEG kateteri takildi.

Kateter tıkanması: Iki (\%12) hastada Foley kateterde tıkanma gelişti (17. ve 27. gün). Bu hastalara da tıkalı olan Foley kateter çekilerek standart PEG kateteri takıldı.
Tablo 1. Hastaların demografik verileri ve PEG takılma endikasyonları

$\begin{array}{lc}\text { Değişken } & \text { Sayı } \\ \text { Hasta sayısı } & 17 \\ \text { Yaş } & 78(60-92) \\ \text { Cinsiyet (E/K) } & 8 / 9 \\ \text { Demans } & 10 \\ \text { Serebrovasküler hastalık } & 6 \\ \text { Malignite } & 1\end{array}$

PEG: Perkütan endoskopik gastrostomi.

Katetere bağlı ülser ve gastrointestinal kanama: Bir (\%6) hastada Foley kateter takıldıktan 37 gün sonra melena ve hematemez gelişmesi nedeni ile yapılan endoskopide antrumda, muhtemelen Foley kateter balonunun temas ettiği alanlarda oluşan büyüğü $2 \mathrm{~cm}$ boyutunda üzeri beyaz eksudalı ülserler saptandı (Resim 2). Kanama endoskopik müdahaleye gerek kalmadan medikal tedavi ile kontrol edildi. Sonrasinda bu hastada da Foley kateter çekilerek standart PEG kateteri takildl.

Kateter migrasyonuna bağlı ileus: Bir (\%6) hasta bulantı-kusma, karın ağrısı ile başvurdu ve Foley kateterin migrasyonuna sekonder ileus geliştiği saptandı. Balon söndürülüp kateter geri çekilince klinik tablo düzeldi. Foley kateter çıkarılarak yerine standart PEG kateteri takıldı.

Komplikasyon gelişmeyen 9 (\%53) hastadan 3 tanesi Foley kateter ile beslenmeye devam ederken primer hastalığına bağlı exitus oldu. 3 hastada komplikasyon olmaksızın kullanım zorluğu ve hasta yakınlarının talebi ile standart PEG katete- 


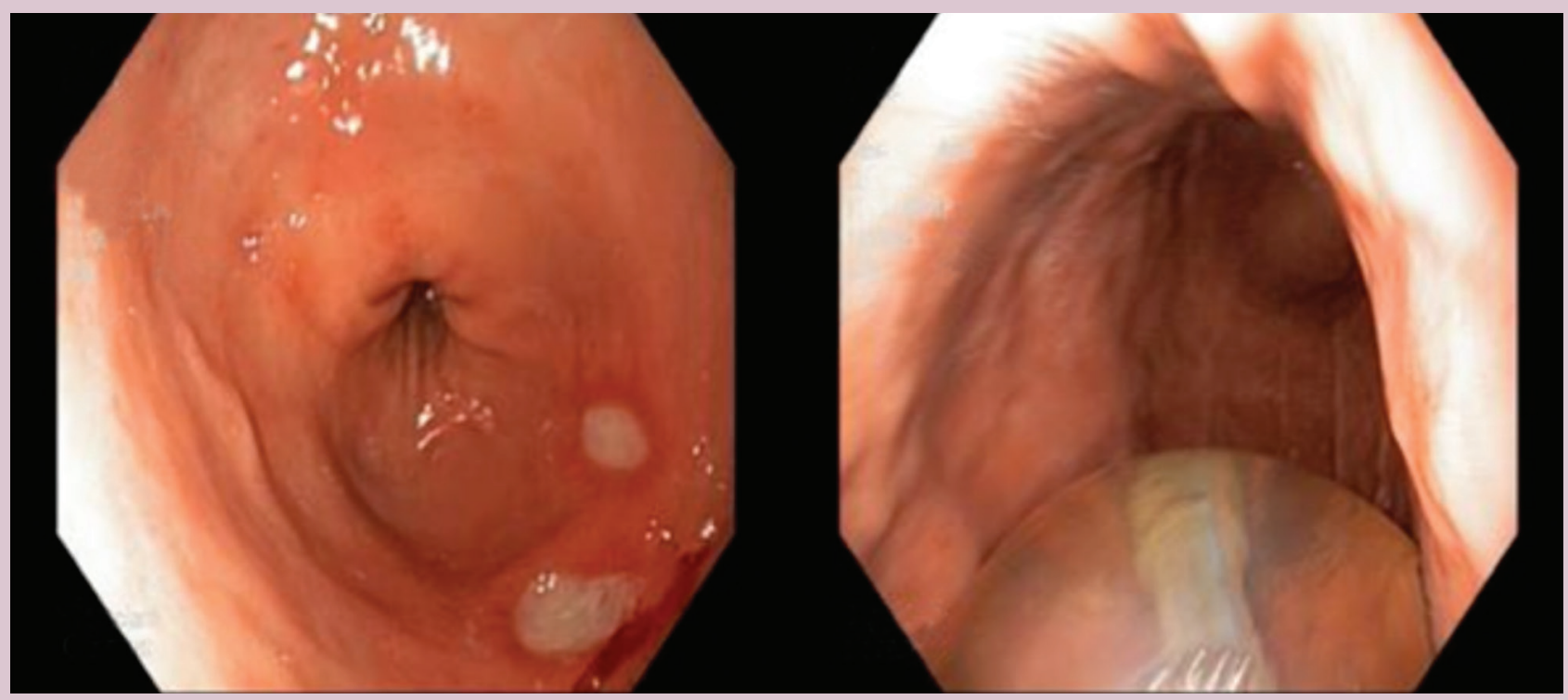

Resim 2. Foley kateter uygulamasına bağlı gelişen ülser.

rine geçildi. 3 hastada aralıklı değişimlerle birlikte Foley kateter kullanımı devam etti. Bu grupta Foley kateter ile takip süresi medyan 6 hafta (1-74 hafta) olarak saptandı.

Genel olarak bakıldığında Foley kateter takarak takip ettiğimiz 17 hastanın sadece 6'sinda (\%35) Foley kateter kullanımı kalıcı olabilmiştir. Sekiz (\%47) hastada komplikasyon, 3 hastada (\%18) ise kullanım zorluğu nedeniyle Foley kateter kullanımından vazgeçilmek zorunda kalınmıştır.

\section{TARTISMA}

PEG kateteri yerine Foley kateter takılması geçmişten beri kullanılan tartışmalı bir durumdur. Bu konuda literatürde çalışmalar mevcuttur $(4,5)$. Yine balonlu PEG kateterleri de günlük kullanımda mevcuttur. Foley kateter yerleştirilirken endoskopik işlem gerektirmemesi ve yatak başı uygulanabilmesi hasta popülasyonu göz önüne alındığında avantaj sağlamaktadır. Foley kateterin PEG kateterinden çok daha ucuz olması ve kolay temin edilebilmesi diğer avantajlarıdır. Biz çalışmamızda komplikasyon gelişmeyen grupta \%35 hastada Foley kateter ile en uzun 74 haftalık bir takip süresine ulaştık. Literatürde komplikasyon gelişmeyen grupta \%28,5 hastada en çok 77 hafta süre ile takip edilen hastalar mevcuttur (6). Bizim sonuçlarımız literatüre benzerdir. Bizim çalışmamızda komplikasyon gelişmeyen gruptaki medyan takip süremiz 6 haftadır. Literatüre bakıldığında medyan takip süresi bildiren çalışma bulunamadı.

Foley kateter kullanımı ile ilgili kateter balonunun sönmesi ve kateter tıkanması bildirilmiş komplikasyonlardır $(6,7)$. Bu komplikasyonlar bizim çalışmamızda sırası ile \%18 ve \%12 oranında saptandı. Literatürde ise \%19 ve \%5 oranında oldu- ğu görüldü (6). Hasta sayısının az olmasını dikkate alındığında bu komplikasyonları literatüre benzer oranlarda bulduk.

Foley kateter migrasyonuna bağlı komplikasyonlar değerlendirildiğinde literatürde akut pankreatit vakaları bildirilmiştir (8). Biz çalışmamızda akut pankreatit komplikasyonu saptamadik. Yine migrasyona bağlı ileus tablosu literatürde \%19'a varan oranlarda bildirilmiştir (6). Bizim çalışmamızda bu oran \%6'dır. Migrasyona bağlı komplikasyonlar kateter balonunu söndürüp kateter geri çekilerek kolay bir şekilde kontrol edilebilmektedir (6). Biz çalışmamızda migrasyonu önlemek için daha önce çıkmış olan PEG kateterinin cilt sabitleyicisini veya bu amaçla kullanılabilecek başka bir cilt sabitleyiciyi önce Foley kateter üzerine yerleştirip sonra kateteri hastaya taktık. Literatüre göre bu komplikasyonun daha az görülmesi bunu etkin olarak uygulamamız ile açıklanabilir. Literatürde de kateter migrasyonunu önlemek için cilde giriş yerini plastik halka benzeri bir cisim ile sabitlemek önerilmektedir (5). Bunun ileus ve akut pankreatit gibi migrasyona bağlı komplikasyonları azalttığı tespit edilmiştir (5).

Biz çalışmamızda literatürde olmayan ancak kateter migrasyonu ve balonun mide duvarına basısına bağlı olduğunu düşündüğümüz ülser ve kanama saptadık.

PEG kateter yerine Foley kateter kullanımı özellikle yaşam beklentisi düşük hastalarda daha az invaziv, pratik ve ekonomik bir alternatif olarak düşünülebilir. PEG takılan hasta popülasyonu göz önüne alındığında endoskopi gerektirmemesi büyük avantajdır. Ancak Foley kateteri takılan hastaların yarısından çoğunda standart PEG kateterine geri dönmek gerekebilir. Ayrıca olası ciddi komplikasyonlar (migrasyona ikincil ileus, kanama) yönünden hastalar yakından takip edilmelidir. 


\section{KAYNAKLAR}

1. Gauderer MW, Ponsky JL, Izant RJ Jr. Gastrostomy without laparotomy: a percutaneous endoscopic technique. J Pediatr Surg 1980;15:872-5.

2. Gauderer MW. Percutaneous endoscopic gastrostomy-20 years later: a historical perspective. J Pediatr Surg 2001;36:217-9.

3. Rahnemai-Azar AA, Rahnemaiazar AA Naghshizadian R, Kurtz A, Farkas DT. Percutaneous endoscopic gastrostomy: indications, technique, complications and management. World J Gastroenterol 2014;20:773951.

4. Kadakia SC, Cassaday M, Shaffer RT. Prospective evaluation of Foley catheter as a replacement gastrostomy tube. Am J Gastroenterol 1992;87:1594-7.

5. Kadakia SC, Cassaday M, Shaffer RT. Comparison of Foley catheter as a replacement gastrostomy tube with commercial replacement gastrostomy tube: a prospective randomized trial. Gastrointest Endosc 1994:40:188-93.
6. Metussin A, Sia R, Bakar S, Chong VH. Foley catheters as temporary gastrostomy tubes: Experience of a nurse-led service. Gastroenterol Nurs 2016:39:273-7.

7. Cassaday M1, Kadakia SC, Yamamoto K, Parker A. Foley feeding catheter migration into the small bowel. J Clin Gastroenterol 1992;15:242-4

8. Shah AM, Shah N, DePasquale JR. Replacement gastrostomy tube causing acute pancreatitis: Case series with review of literature. JOP. J Pancreas (Online) 2012;13:54-7. 